\title{
Health impact assessment of Delhi's outdoor workers exposed to air pollution and extreme weather events: an integrated epidemiology approach
}

\author{
Vaishnavi Barthwal ${ }^{1}$ Suresh Jain ${ }^{2}$ (I) $\cdot$ Ayushi Babuta ${ }^{1} \cdot$ Chubamenla Jamir $^{1} \cdot$ Arun Kumar Sharma $^{3} \cdot$ Anant Mohan $^{4}$
}

Received: 18 October 2021 / Accepted: 21 January 2022 / Published online: 9 February 2022

(c) The Author(s), under exclusive licence to Springer-Verlag GmbH Germany, part of Springer Nature 2022

\begin{abstract}
This study is an assessment of the effects of outdoor air pollution and extreme weather events on the health of outdoor workers in Delhi, including auto rickshaw drivers, street vendors, and sweepers. To carry it out, a cross-sectional and perception-based epidemiological research design was used, and the primary tool used for data collection was a questionnaire. Two hundred twenty-eight people participated in the survey, and a pulmonary function test (PFT) was performed on 63 participants. Most of the respondents from different occupational groups complained about headaches/giddiness, nausea, and muscular cramps during extreme heat events due to the physically demanding nature of their jobs in the outdoor environment. Furthermore, autorickshaw drivers reported the highest prevalence of ophthalmic symptoms, such as eye redness (44\%) and eye irritation (36\%). In comparison, vendors reported a higher prevalence of headaches (43\%) and eye redness (40\%) due to increased exposure to vehicular emissions. Among sweepers, musculoskeletal problems like joint pain (40\%), backache (38\%), and shoulder pain (35\%) were most prevalent due to occupation-related ergonomic factors. In addition, the majority of autorickshaw drivers (47\%), vendors (47\%), and sweepers (48\%) considered that air quality had a severe impact on their health. PFT results showed that most respondents had restricted lung function. Binary logistic regression analysis showed that lung function impairment had a significant association with smoking $(p=0.023)$ and age $(0.019)$. The odds ratio for smoking, which was around 4, indicated that respondents who smoked had a nearly four times greater risk of developing lung impairment. The study also highlighted the need for using personal protective equipment and developing guidelines to reduce their exposure level.
\end{abstract}

Keywords Street vendors · Pulmonary function test - Outdoor pollution · Occupational exposure $\cdot$ Epidemiological approach $\cdot$ Cross-sectional study

\section{Introduction}

Responsible Editor: Lotfi Aleya

Suresh Jain

sureshjain_in@yahoo.com; sureshjain@iittp.ac.in

1 Department of Energy and Environment, TERI School of Advanced Studies (earlier TERI University), Delhi, 10, Institutional Area, Vasant Kunj, New Delhi 110 070, India

2 Department of Civil \& Environmental Engineering, Indian Institute of Technology Tirupati, Tirupati, Andhra Pradesh 517 506, India

3 University College of Medical Sciences, University of Delhi, New Delhi, India

4 Department of Pulmonary Medicine \& Sleep Disorders, All India Institute of Medical Sciences, New Delhi, India
Human health is adversely affected by exposure to occupational and environmental exposure and extreme weather conditions. Outdoor workers, particularly those in the informal sector, such as autorickshaw drivers, street sweepers, construction workers, and street vendors, are more susceptible to occupational exposure as little or no attention is paid to their health by the authorities. They are exposed to multiple occupational risks due to road dust, construction dust, vehicular emissions, industrial fumes, and more (Jain and Barthwal 2021; Levy and Roleofs 2019; Noomnual and Shendell 2017; Loomis et al. 2013; Carvalho et al. 2018; NIEHS 2015). An analogous situation has been observed in traffic hotspots of Accra, Ghana, in the case of street traders who were found to be exposed to $\mathrm{PM}_{2.5}$, which increased 
the occurrence of respiratory and cardiovascular symptoms among them (Amegah et al. 2021).

Furthermore, extreme weather events tend to decrease the efficiency and productivity of these groups of workers and expose them to unhealthy working conditions ( $\mathrm{Li}$ et al. 2016). In addition, socio-economic and demographic factors, such as age, gender, low income, malnutrition, preexisting diseases, lack of access to adequate clothing and shelter, and intensive physical activity, increase their susceptibility to extreme weather conditions (Lundgren et al. 2013; Kravchenko et al. 2013). For instance, $\sim 49 \%$ of street sweepers in Dessie City, Ethiopia, were found to be suffering from acute respiratory infections, owing to factors like nonuse of masks while sweeping, personal protective equipment not being cleaned after use, and the use of coal/ wood for cooking (Eneyew et al. 2021).

In developed countries, occupational health and safety are given due importance. However, in the case of developing countries, these issues are usually neglected, and workers are left without proper protection and safety equipment (Eneyew et al. 2021). In a cross-sectional study on street vendors in Bangkok, it was found that $53 \%$ of respondents had never used protective equipment (Noomnual and Shendell 2017). In India, millions of workers are engaged in physically demanding jobs like agriculture, stone grinding, construction work, sweeping, and vending work without protection and are thus exposed to extreme conditions and other occupational hazards (Johncy et al. 2013; Nag et al. 2013).

Lack of cooling facilities along with improper ventilation in their work areas result in a negative impact on the health of workers, which includes heat exhaustion, heat cramps, headache, and severe heat stress and injuries (Schulte et al. 2016; Xiang et al. 2014a; Nag et al. 2013). The potential causes for injuries under such conditions may be sweaty palms, unintentional contact with a hot surface, fogged-up safety glasses, and loss of concentration and coordination (Xiang et al. 2014b). In Ahmedabad, 1344 deaths were reported due to heatwaves in 2010; the victims included many outdoor workers (AHAP 2016). Furthermore, during winter, due to poor insulation and shelter, workers are more susceptible to musculoskeletal problems like body and joint pain, resulting in increased chances of accidents and injuries. In addition, a higher pollution level during winter aggravates respiratory and cardio-vascular problems especially, for outdoor workers (Hajat et al. 2016; NIEHS 2015; Chashchin et al. 2014).

Air pollution contributes to a large proportion of the global burden of disease, including ophthalmic, respiratory, cardiovascular, and dermatological symptoms (Monrad et al. 2017). In Indian megacities like Delhi, the increased number of vehicles, resuspension of dust particles, construction activities, biomass burning, and other unregulated anthropogenic activities have been responsible for the deteriorating ambient air quality (Liu et al. 2018; Tonne 2017; Jain 2017; Jain et al. 2016; Kumar et al. 2013). In the last two decades, the air pollution level in Delhi has augmented drastically, leading to increased morbidity in the form of chronic respiratory diseases, acute cardiovascular events, reproductive and developmental damage, allergies, and cancers, as well to a higher mortality rate (Jain et al. 2021; Jain and Sharma, 2020; Biel et al. 2020; Kumar and Mishra 2018; Landrigan et al. 2017; Jain et al. 2016; Aggarwal and Jain 2015).

Furthermore, Delhi is subject to extreme events of heat and cold waves due to its geographic location and topography. In the summer months (April-July), the temperature varies from $25-46{ }^{\circ} \mathrm{C}$ while, in the winter months (December-January), the temperature varies from a minimum of 3 to $22{ }^{\circ} \mathrm{C}$. It is often foggy, which increases air pollution levels (Statistical Abstract of Delhi, 2016, GNTCD, 2017). The result is compounded health impacts on outdoor workers (Tiwari et al. 2018; Bajaj et al. 2017; Kumar et al. 2013). Therefore, we attempted to assess and compare the health effects of ambient air pollution and extreme weather events on three groups of outdoor workers in Delhi, i.e., autorickshaw drivers, street vendors, and sweepers, using an integrated approach, i.e., a cross-sectional perception-based survey, the opinion of medical experts and outcomes of lung function tests.

\section{Methodology}

To assess the health of outdoor workers as it was affected by their occupational exposure to ambient pollution and extreme weather events, the study used a cross-sectional perception-based epidemiological approach along with PFT, as shown in Fig. 1.

\section{Study area and site selection}

The study area was the National Capital Territory of Delhi (NCT of Delhi) $\left(28.7041^{\circ} \mathrm{N}, 77.1025^{\circ} \mathrm{E}\right)$. The NCT of Delhi has an area of $1483 \mathrm{sq} . \mathrm{km}$. and is divided into eleven districts (GNCTD, 2012; Census of India 2011). For data collection, stratified random sampling was carried out. The study area was divided into three strata per Central Pollution Control Board (CPCB) criteria-residential, commercial, and industrial. The locations were randomly selected from eleven district zones for each stratum (Fig. 2).

\section{Research design}

A structured questionnaire was designed for data collection comprising questions related to personal information, sociodemographic aspects, work details (number of working $\mathrm{h}$ / day, working days, period from which individual working), 
Fig. 1 Framework for health impact assessment of outdoor workers

Fig. 2 Map of the study area

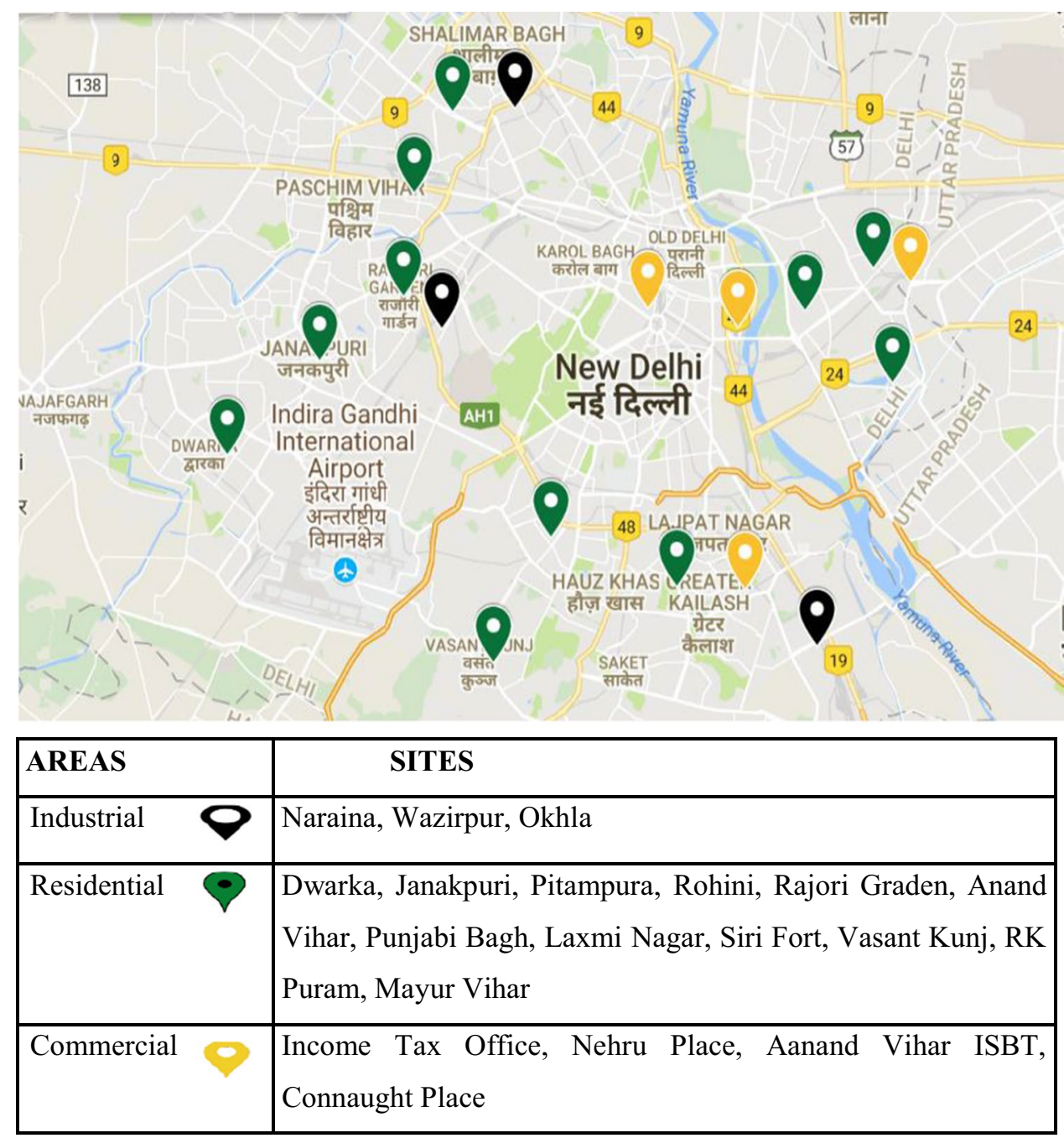

Critical review of research papers, review articles, newspaper articles etc.

Thematic area: Occupational Exposure and Health Impacts Assessment

\begin{tabular}{|c|c|c|c|c|}
\hline \multicolumn{5}{|c|}{$\begin{array}{l}\text { Critical review of research papers, review articles, newspaper articles etc. } \\
\text { Thematic area: Occupational Exposure and Health Impacts Assessment }\end{array}$} \\
\hline \multicolumn{5}{|c|}{ Perception Survey } \\
\hline \multicolumn{4}{|c|}{ Subjects: Autorickshaw drivers; Street vendors and Street sweepers } & \multirow{4}{*}{$\begin{array}{l}\text { Questionnaire Design for } \\
\text { Expert opinion; } \\
\text { Pilot testing \& Validation }\end{array}$} \\
\hline $\begin{array}{l}\text { Exposure } \\
\text { Duration }\end{array}$ & $\begin{array}{l}\text { Socio-demographic } \\
\text { Attributes }\end{array}$ & $\begin{array}{l}\text { Health Data } \\
\text { (Morbidity) }\end{array}$ & \multirow{3}{*}{$\begin{array}{l}\text { Spirometric } \\
\text { Analysis }\end{array}$} & \\
\hline $\begin{array}{l}\text { Exposure } \\
\text { cycle }\end{array}$ & $\begin{array}{c}\text { Influencing Factors: } \\
\text { Age, Body Mass Index, } \\
\text { Alcohol, Smoking and } \\
\text { Tobacco }\end{array}$ & $\begin{array}{l}\text { Prevalence } \\
\text { of Disease } \\
\text { Symptoms } \\
\end{array}$ & & \\
\hline \multicolumn{3}{|c|}{$\begin{array}{c}\text { Statistical Analysis: Binomial Regression and } \\
\text { Chi-square test }\end{array}$} & & \\
\hline
\end{tabular}

Health impacts assessment and factors influencing prevalence of disease symptoms 
adverse health events during extreme weather conditions. These symptoms were identified through a comprehensive literature review and in consultation with medical experts. The questionnaire was tested during a pilot survey with 30 participants. The necessary changes were made in the questionnaire after discussion with experts in the air quality field and healthcare professionals based on pilot testing, and these responses were not included in the analysis.

\section{Study population}

Spirometry (office-based PFT) was used to determine the functional status of lungs (Babu et al. 2017; Johnson and Theurer 2014; Messan et al. 2013; Barreiro and Perillo 2004). It measures the rate of change in lung volume during forced breathing maneuvers. The test is initiated with a full inhalation, followed by forced expiration such that the lungs empty rapidly (Johnson and Theurer 2014; Barreiro and Perillo 2004). Vitalograph 6000 alpha comprising of PFT software, printer, pneumotach, disposable mouthpieces, nosepiece, and calibration syringe was used for the PFT (Sharma and Nepalia 2020; Tigala et al. 2018; Johnson and Theurer 2014). The subjects who had recently undergone surgery or had acute problems like nausea and vomiting were not considered for the test (Sharma and Nepalia 2020). A disposable mouthpiece was given to each subject to perform the test. It was ensured that the mouthpiece was not obstructed by teeth or tongue and that the subject's lips were tightly sealed around the mouthpiece to avoid any leakage of air, and the nose was pinched with a nose clip (Miller et al. 2005).

The PFT procedure required at least three acceptable maneuvers, of which the best two were used for interpreting the results (Johnson and Theurer 2014; Barreiro and Perillo 2004). Forced vital capacity (FVC), forced expiratory volume in the first second (FEV1), and FEV1/FVC ratio was used to determine the ventilatory impairment if any (Johnson and Theurer 2014; Barreiro and Perillo
2004). Lung function was categorized as restrictive, obstructive, or usual by assessing the FVC, FEV1 values, and FEV1/FVC ratio (Fig. 3). Medical experts from the All India Institute of Medical Science (AIIMS) and Maulana Azad Medical College facilitated hands-on practice and understanding of PFT before the test was conducted and the test interpretations were cross-checked/ validated.

\section{Statistical analysis}

The data analysis was done using MINITAB Software version 18 and Microsoft Excel 2016 (Data analysis tool pack). Data were assessed to compare the prevalence of health symptoms among the occupational groups as well as the influence of personal habits and demographic factors such as smoking, tobacco consumption, age, etc. Since the data for disease symptoms were categorical, Pearson's chi-squared test was used to determine whether the risk of health symptoms was higher in a particular occupational group. This test primarily assesses the association between two categorical responses or differences between the study groups in the proportion of the risk factor of interest. Data were arranged in contingency tables for analysis, and a p-value of $<0.05$ was considered statistically significant (Shih and Fay 2017; Rana and Singhal 2015).

Binomial logistic regression (BLR) was used to determine the influence of age, body mass index (BMI), smoking, and tobacco consumption on the occurrence of impaired lung function at a 95\% confidence interval. BLR is used when the dependent variable is dichotomous, e.g., presence or absence of a disease/symptom, and the independent variables continuous, e.g., age, weight or categorical, e.g., race, ethnicity (Pintakham and Siriwong 2016; Harell 2015; Sreejesh et al. 2014; Abou-ElWafa et al. 2014). In the present study, the occurrence of lung impairment was the dependent dichotomous variable.
Fig. 3 Criteria for interpreting pulmonary function test results

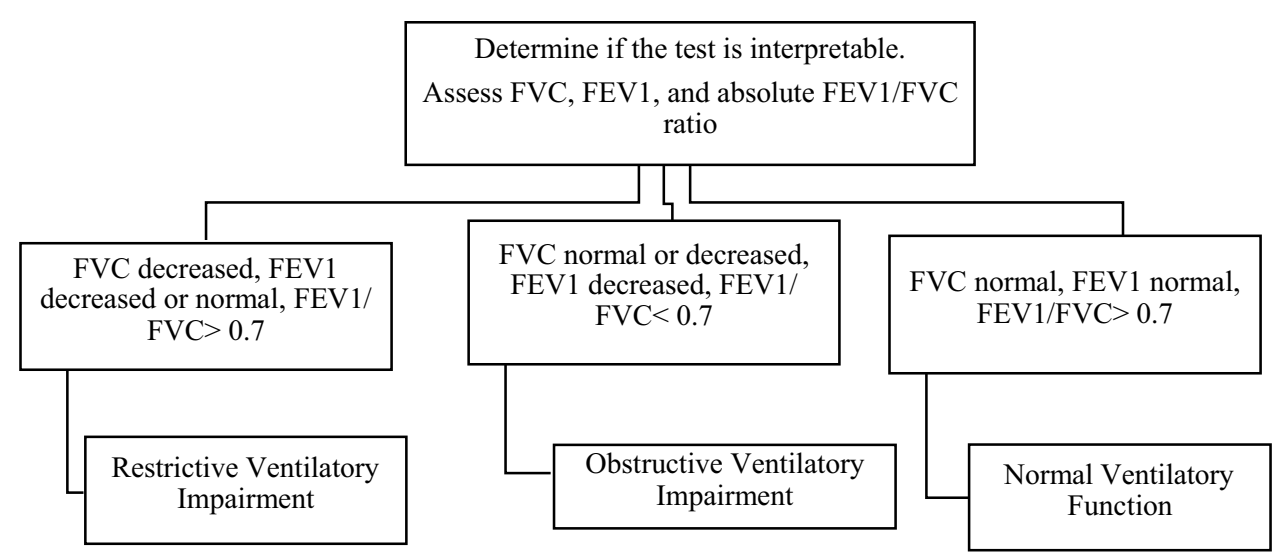




\section{Results}

\section{General charactesec 3 ristics and perception of respondents}

The general characteristics of each occupational group

Table 1 Summary of data collected from outdoor workers through questionnaire survey

\begin{tabular}{|c|c|c|c|}
\hline Total respondents & 228 & & \\
\hline $\begin{array}{l}\text { Pulmonary function } \\
\text { test }\end{array}$ & 63 & & \\
\hline Occupational group & $\begin{array}{l}\text { Autorickshaw } \\
\text { drivers }\end{array}$ & Vendors & Sweepers \\
\hline Respondents & 78 & 75 & 75 \\
\hline Age (years) & $39 \pm 10.52$ & $35 \pm 13.95$ & $41 \pm 9.42$ \\
\hline Height (cm) & $166.5 \pm 6.64$ & $162.4 \pm 7$ & $160 \pm 21.03$ \\
\hline Weight $(\mathrm{kg})$ & $64.8 \pm 23.35$ & $58 \pm 13.17$ & $67 \pm 13.71$ \\
\hline Males & $100 \%$ & $96 \%$ & $87 \%$ \\
\hline Females & $0 \%$ & $4 \%$ & $13 \%$ \\
\hline BMI & $23.3 \pm 4.06$ & $21.3 \pm 6.04$ & $23.4 \pm 7.05$ \\
\hline Smoking & $35 \%$ & $40 \%$ & $45 \%$ \\
\hline Alcohol & $33.3 \%$ & $32 \%$ & $50 \%$ \\
\hline Tobacco & $41 \%$ & $54 \%$ & $33 \%$ \\
\hline Working h/day & $11.3 \pm 1.8$ & $11.6 \pm 2.7$ & $8.4 \pm 1.2$ \\
\hline \multicolumn{4}{|c|}{ Monthly income (INR) } \\
\hline $1000-5000$ & $0 \%$ & $9 \%$ & $7 \%$ \\
\hline $5000-10,000$ & $13 \%$ & $43 \%$ & $21 \%$ \\
\hline $10,000-15,000$ & $37 \%$ & $36 \%$ & $25 \%$ \\
\hline $15,000-25,000$ & $40 \%$ & $11 \%$ & $9 \%$ \\
\hline$>25,000$ & $10 \%$ & $1 \%$ & $38 \%$ \\
\hline \multicolumn{4}{|c|}{ Distance traveled (km/day) } \\
\hline $0-10$ & $0 \%$ & $67 \%$ & $54 \%$ \\
\hline $10-20$ & $0 \%$ & $23 \%$ & $24 \%$ \\
\hline $20-30$ & $0 \%$ & $6 \%$ & $15 \%$ \\
\hline$>30$ & $100 \%$ & $4 \%$ & $7 \%$ \\
\hline \multicolumn{4}{|l|}{ Education } \\
\hline None & $23 \%$ & $35 \%$ & $42 \%$ \\
\hline Primary & $15 \%$ & $17 \%$ & $10 \%$ \\
\hline Secondary & $30 \%$ & $35 \%$ & $38 \%$ \\
\hline Higher secondary & $23 \%$ & $8 \%$ & $9 \%$ \\
\hline $\begin{array}{l}\text { Graduation and } \\
\text { higher }\end{array}$ & $9 \%$ & $5 \%$ & $1 \%$ \\
\hline \multicolumn{4}{|c|}{ Type of fuel used for cooking } \\
\hline Coal & $6 \%$ & $1 \%$ & $6 \%$ \\
\hline LPG & $86 \%$ & $76 \%$ & $83 \%$ \\
\hline PNG & $0 \%$ & $1 \%$ & $1 \%$ \\
\hline Wood/biomass & $3 \%$ & $10 \%$ & $8 \%$ \\
\hline Gas/biomass & $4 \%$ & $8 \%$ & $2 \%$ \\
\hline Others & $1 \%$ & $1 \%$ & $0 \%$ \\
\hline None & $0 \%$ & $3 \%$ & $0 \%$ \\
\hline
\end{tabular}

included in the study are summarized in Table 1 . The data show that autorickshaw drivers traveled maximum distance, which makes them more vulnerable as they will expose more to air pollution and extreme weather during their work. It is also observed that autorickshaw drivers and street vendors are more educated compared to street sweepers. It was also found that autorickshaw drivers and street vendors spend 47 and $48 \%$ of the day at their workplaces, while sweepers spend only $35 \%$ of their day at the workplace (Table 2A). The majority of autorickshaw drivers (48\%) and sweepers (32\%) perceived the air quality at their workplace as being hazardous, while a majority of vendors (39\%) considered it unhealthy (Table 2B). Almost 2/3rd of outdoor workers feel that indoor air quality is not good (Table $2 \mathrm{C}$ ). The majority of the respondents from all occupational groups (47\% autorickshaw drivers and vendors, $48 \%$ sweepers) perceived that air quality severely impacted their health (Table 2D). Some sweepers complained of irritation in the eyes and coughing due to resuspension of road dust while sweeping.

Table 2 Perceptions of occupational groups about air quality and its impact-A exposure cycle at various microenvironment; $\mathbf{B}$ air quality at their workplaces; $\mathbf{C}$ indoor air quality at their houses; $\mathbf{D}$ impact of air quality on their health

\begin{tabular}{llll}
\hline Activities & $\begin{array}{l}\text { Autorickshaw } \\
\text { drivers }\end{array}$ & Street vendors & Sweepers \\
\hline
\end{tabular}

A. Exposure cycle-time spent in various microenvironments (\% of $24 \mathrm{~h}$ )

$\begin{array}{llll}\text { Home } & 44 & 45 & 54 \\ \text { Workplace } & 47 & 48 & 35 \\ \text { Transit/travel } & 3 & 5 & 5 \\ \text { Outdoor } & 6 & 2 & 6\end{array}$

B. How would you rate the air quality in your working areas? (in \%)

$\begin{array}{llll}\text { Excellent } & 1 & 3 & 0 \\ \text { Good } & 4 & 5 & 18 \\ \text { Moderate } & 22 & 25 & 25 \\ \text { Unhealthy } & 24 & 39 & 18 \\ \text { Hazardous } & 48 & 21 & 32 \\ \text { Not aware } & 1 & 7 & 7\end{array}$

C. How would you rate the air quality inside your house? (in \%)

$\begin{array}{llll}\text { Excellent } & 6 & 4 & 12\end{array}$

$\begin{array}{llll}\text { Good } & 22 & 32 & 25\end{array}$

$\begin{array}{llll}\text { Moderate } & 24 & 34 & 28\end{array}$

$\begin{array}{llll}\text { Unhealthy } & 26 & 13 & 10\end{array}$

$\begin{array}{llll}\text { Hazardous } & 22 & 12 & 19\end{array}$

$\begin{array}{llll}\text { Not aware } & 0 & 5 & 6\end{array}$

D. How would you rate the impact of air quality on your health? (in $\%)$

$\begin{array}{llll}\text { No impact } & 15 & 20 & 10 \\ \text { Mild impact } & 17 & 17 & 18 \\ \text { Moderate impact } & 21 & 16 & 24 \\ \text { Severe impact } & 47 & 47 & 48\end{array}$


It was the view of all occupational groups that the main source of air pollution was vehicular emissions (Fig. S1, SI Section S3).

Most autorickshaw drivers thought that $\mathrm{CNG}$ vehicles were the cause of pollution, while some considered diesel vehicles to be the only contributors to air pollution. Furthermore, road dust was pointed to as a cause of pollution mainly by sweepers (11\%) compared to the other two occupational groups. Some sweepers also said that the burning of waste and biomass contributed to air pollution. The study was carried out during the summer months; thus, there might be perception bias in the responses of the subject population, which provides scope to conduct a longitudinal study in the future.

This section further elaborates the prevalence of disease symptoms, the effect of extreme weather events, PFT, and the effect of personal habits, such as smoking, tobacco use, and alcohol consumption, on the health of different groups of outdoor workers considered in the study.

\section{Prevalence of disease symptoms}

The prevalence of disease symptoms among the three groups of outdoor workers did not differ significantly $(p>0.05)$, suggesting that all outdoor workers are equally vulnerable to health impacts due to occupational exposure (Table A in SI, Section S2).

\section{Respiratory symptoms}

Among respiratory symptoms, chronic cough, breathlessness, and phlegm were the most prevalent among all three occupational groups. Chronic cough (24\%) and phlegm (21\%) were was most prevalent among sweepers, while breathlessness was the most prevalent among vendors (31\%) (Fig. 4a).

\section{Ophthalmic symptoms}

Eye irritation, redness, and watering were the most prevalent symptoms among all three groups. All these symptoms were most prevalent among autorickshaw drivers $(44 \%, 36 \%$, $31 \%)$, followed by vendors $(40 \%, 35 \%, 31 \%)$, and sweepers $(34 \%, 32 \%, 26 \%)$ (Fig. 4b).

\section{Musculoskeletal symptoms}

The occurrence of musculoskeletal symptoms among all the three groups considered can be attributed to the physically demanding nature of their jobs as well as their long working hours. All musculoskeletal symptoms (backache, shoulder pain, and joint pain) were most prevalent among street sweepers $(38 \%, 35 \%, 40 \%)$. In addition, $37 \%$ of autorickshaw drivers complained of backache, and 39\% of vendors complained of joint pain (Fig. 4c).

\section{Dermatological symptoms}

Among dermatological symptoms, skin rashes were most prevalent among street vendors (23\%), while skin redness (16\%) and itching (17\%) were most prevalent among sweepers and autorickshaw drivers, respectively (Fig. 4d).

\section{Cardiovascular symptoms}

Cardiovascular symptoms were reported to be prevalent among less than $10 \%$ of the members of each occupational group. Chest pain was prevalent among $8 \%$ of vendors and $9 \%$ sweepers, while $9 \%$ of autorickshaw drivers complained of irregular heartbeat and chest discomfort (Fig. 4e).

\section{General symptoms}

Among general health symptoms, headache and weakness were the most prevalent among members of all three groups (Fig. 4f). Both these symptoms were most prevalent among autorickshaw drivers $(44 \%, 41 \%)$, followed by street vendors $(43 \%, 37 \%)$ and sweepers $(38 \%, 37 \%)$. These symptoms may also be attributed to long working hours and the physically demanding nature of the jobs of these outdoor workers.

\section{Health impacts due to extreme weather events}

The highest temperature in Delhi during the summer months (April-June) was $47^{\circ} \mathrm{C}$ on certain days and above $40^{\circ} \mathrm{C}$ on most days, while during the winter months (December-February), the lowest temperatures were between $4-18{ }^{\circ} \mathrm{C}$. To assess the health impacts of extreme weather events on the subjects, health symptoms evident during high temperatures (headache, giddiness, nausea, vomiting, and fainting) and low temperatures (shivering and slurred speech) were considered. Headache/giddiness were the most prevalent symptoms among all occupational groups, followed by rapid heartbeat, muscle cramps, nausea and vomiting, and red, hot, dry skin during extreme heat events. Most of these symptoms were highest among vendors (headache/giddiness $75 \%$, rapid heartbeat $36 \%$, fainting/unconsciousness $20 \%$ ); next highest among sweepers $(60 \%, 34 \%, 15 \%)$ followed by auto drivers $(54 \%, 27 \%, 5 \%)$ (Fig. 4g). On the whole, during extreme cold events, there were fewer instances than during heatwaves of subjects being affected by symptoms (Fig. 4h).

However, shivering and headache/giddiness were the most prevalent symptoms during extreme cold events, with shivering (19\%) being the most prevalent among vendors and headache/giddiness (14\%) among autorickshaw drivers. All other symptoms like slurred speech, slow pulse, and 

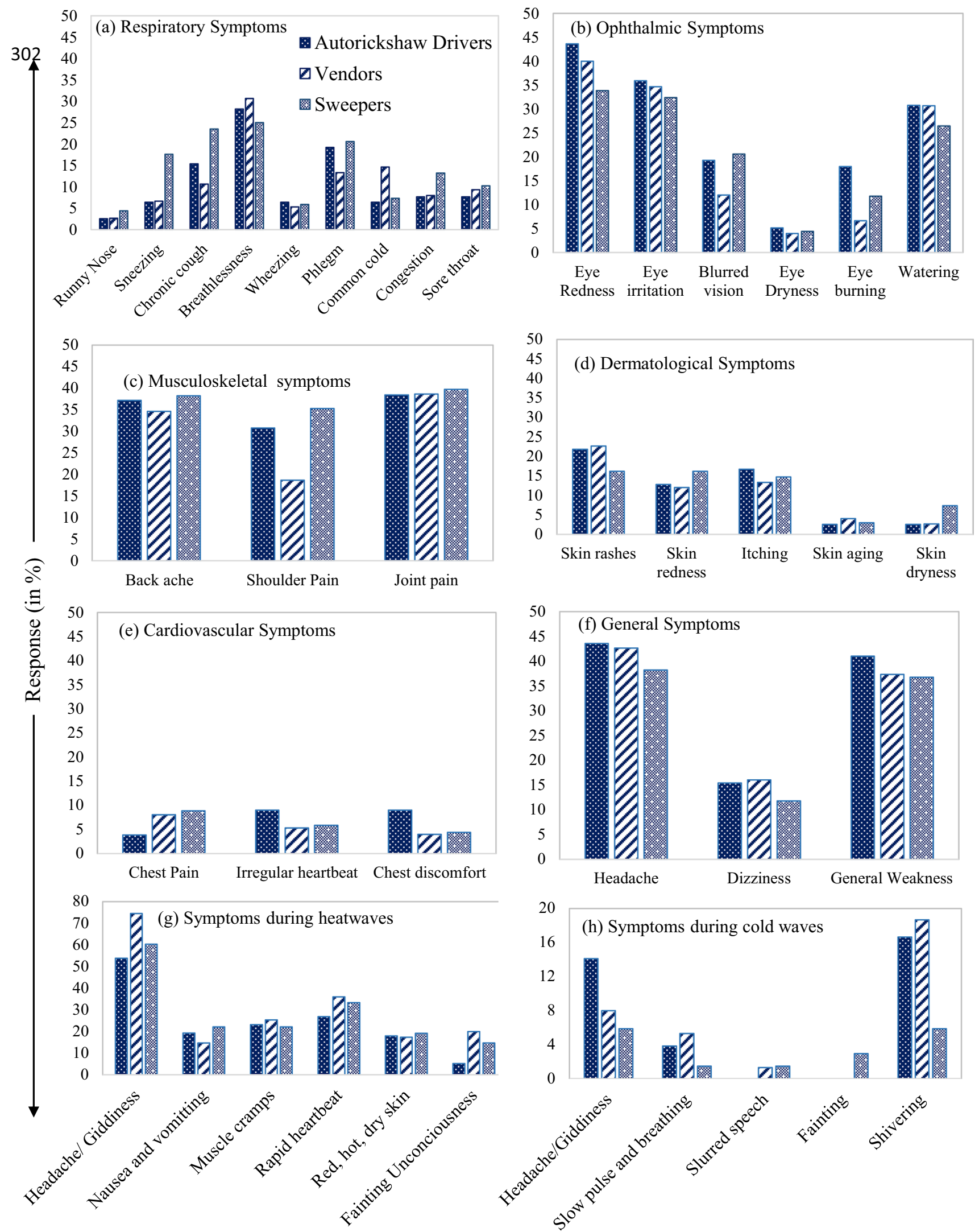

Fig. 4 Prevalence of disease symptoms among all three categories of outdoor workers (in percentages) 
fainting were significantly less prevalent $(<10 \%)$. Furthermore, the Chi-square test indicated that the difference in the prevalence of these symptoms during heat and cold was statistically insignificant $(p>0.05)$ among different occupational groups. Moreover, most of the respondents from all occupational groups felt that winter was a more comfortable season in terms of health and ease of working, whereas they said that they faced the most discomfort in the summer months.

On the whole, during extreme cold events, there were fewer instances than during heatwaves of subjects being affected by symptoms (Fig. 4h). However, shivering and headache/giddiness were the most prevalent symptoms during extreme cold events, with shivering (19\%) being the most prevalent among vendors and headache/giddiness (14\%) among autorickshaw drivers. All other symptoms like slurred speech, slow pulse, and fainting were significantly less prevalent $(<10 \%)$. Further, the chi-square test indicated that the difference in the prevalence of these symptoms during heat and cold was statistically insignificant $(p>0.05)$ among different occupational groups. Moreover, most of the respondents from all occupational groups felt that winter was a more comfortable season in terms of health and ease of working, whereas they said that they faced the most discomfort in the summer months.

\section{Perception of respondents about the effect of extreme events on working efficiency and productivity}

Extreme events related to air pollution and weather conditions have been found to adversely impact the health, work efficiency, and productivity of outdoor workers (Moda and Alshahrani 2018; Li et al. 2016). In the present study, workers were thus asked to rank the events related to extreme heatwaves, cold waves, precipitation, and air pollution based on how these events negatively impacted their working ability, on a scale of 1 (maximum impact) to 4 (most negligible impact). Respondents from all the occupational groups faced most problems during extreme heatwaves (59\% autorickshaw drivers, $72 \%$ vendors, $74 \%$ sweepers), followed by precipitation (28\% autorickshaw drivers, $17 \%$ vendors, $15 \%$ sweepers), cold waves ( $8 \%$ autorickshaw drivers, $8 \%$ vendors, $4 \%$ sweepers), and extreme air pollution (5\% autorickshaw drivers, $3 \%$ vendors, $7 \%$ sweepers). Autorickshaw drivers mentioned that during heat waves driving in the noon hours became difficult as they suffered from giddiness and headache. Thus, some of them avoided going out during those hours. Their vehicles also required greater servicing and maintenance during heatwaves and extreme precipitation.

Additionally, they faced a decline in the demand for their work as customers preferred using air-conditioned cabs to travel during heatwave events. Street vendors complained of problems during heatwaves and precipitation due to the lack of proper shelter for them and their goods. The vendors who sold perishable goods ( $85 \%$ ) like food items said that these extreme events caused spoiling of the goods and thus affected their business. Also, lack of shelter and cooling facilities caused health issues, as mentioned in the previous section, affecting their working efficiency. For sweepers, working in extreme heatwaves was difficult as they did not have proper shelter.

Furthermore, street sweepers complained that during high levels of precipitation, overflowing drains and improperly maintained roads made it difficult for them to sweep the streets. In relative terms, cold waves were perceived by the majority of subjects from all the professions included in the study to be the most comfortable for carrying out their functions. Episodic events of extreme air pollution were considered by these groups as having the least impact on their work efficiency. However, the respondents mentioned that, due to their socio-economic conditions, they did not have the option of staying away from work during periods of severe air pollution or extreme weather conditions.

\section{Pulmonary function test}

The results of PFT showed that the prevalence of restrictive lung function was more than obstructive lung function for subjects from all occupational groups (Fig. 5a-c). It was highest among sweepers (39\%), followed by auto drivers (33\%) and street vendors (27\%). Restrictive lung disorder is associated with systemic inflammation, pulmonary fibrosis, and interstitial lung disease (Caronia 2017). BLR results suggested that lung impairment was also significantly associated with smoking $(p=0.045)$ and age $(p=0.023)$. The odds ratio for smoking $(3.38$, CI 1.0297, 11.0983) suggests that the likelihood of respiratory impairment may increase by four times in the case of smokers, as compared to nonsmokers.

\section{Use of personal protective equipment (PPE)}

Most respondents used protective measures such as cloth for headgear and for covering their faces while working outdoors (Figure S2a-c, SI Section S4). However, these precautions do not constitute formal protective measures that offer sufficient protection against air pollution and extreme weather conditions. Only 4\% of sweepers used gloves, while autorickshaw drivers and vendors did not use them. Many sweepers complained that they were not provided with good quality protective equipment. They were highly dissatisfied with their uniform, as it made it difficult for them to work efficiently, especially during summer, as it caused more perspiration and did not allow for ventilation of their skin. Autorickshaw drivers complained about the difficulty of 
Fig. 5 Results of PFT showing prevalence of restrictive lung function (a) Autorickshaw drivers

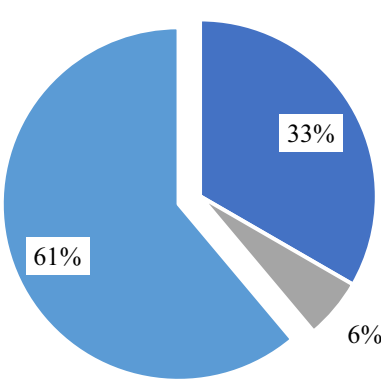

(b) Vendors

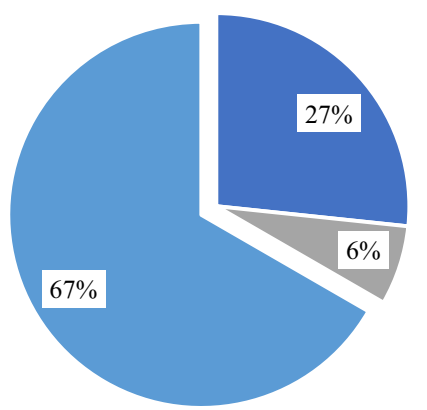

- Restriction $\quad$ Obstruction

- Normal (c) Sweepers

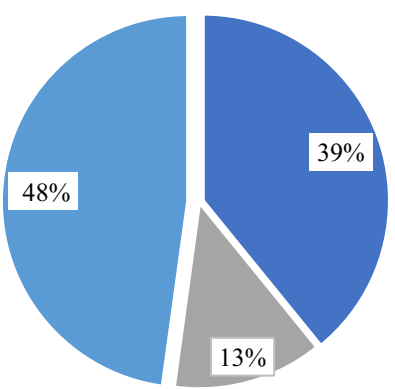

driving when using face masks and said that they preferred using a cloth to cover their faces. Only $2 \%$ of them stayed away from highly polluted routes in order to avoid exposing themselves to extreme air pollution. In addition to these protective measures, most respondents from each occupational group practiced preventive measures like taking breaks to rest in the shade and drinking more water and fluids during extreme heatwaves. A few vendors even used portable fans to cope with heat stress.

\section{Discussion}

\section{Health symptoms}

All the occupational groups included in the study are exposed to emissions from vehicular traffic, road dust, and other ambient air pollutants for long hours each day. The results of our study highlight some of the health symptoms prevalent among these outdoor workers. This section further discusses the findings of the study.

The highest prevalence of ophthalmic symptoms was reported by auto drivers, i.e., eye redness (44\%), eye irritation (36\%), watering (31\%). Furthermore, the same group complained of breathlessness (28\%) and dermatological problems like skin rashes (22\%) and itching (17\%). The reason is likely to be high exposure to vehicular pollution, which has been reported by various studies. Jain (2017), in his study conducted in Delhi, found that in-vehicle concentration of PM in different modes of transport like buses, autorickshaws, and cars was higher than in the ambient air quality standards. The in-vehicle concentration in autorickshaws was almost the same as observed in non-airconditioned cars, without any significant difference. Similarly, the in-vehicle concentration of $\mathrm{PM}_{2.5}$ and black carbon were higher in auto-rickshaws than in closed vehicles (Apte et al. 2011). For instance, the average $\mathrm{PM}_{2.5}$ personal concentration exposure levels in non-air-conditioned cars were reported around $85.41 \pm 61.85 \mu \mathrm{g} / \mathrm{m}^{3}$, as compared to car air-conditioned cars wherein the $\mathrm{PM}_{2.5}$ concentration was $54.43 \pm 34.09 \mu \mathrm{g} \mathrm{m}^{-3}$ (Kolluru et al. 2018). Such traffic-related exposure to various air pollutants can have wide-ranging health impacts (Jain and Barthwal 2021; Liu et al. 2015). Lawin et al. (2016) reported that motorcycle drivers also had significantly greater exposure to $\mathrm{CO}$ from traffic emissions as compared to the control group and had a higher prevalence of cough (5\%), phlegm (6\%), and other respiratory problems. Other general symptoms, such as headache (43.5\%) and general weakness (41\%), and musculoskeletal issues like joint pain (38\%), backache (37\%), shoulder pain $(31 \%)$, among auto-drivers may be due to long working hours and exposure to harsh working conditions (Xiang et al. 2014a; Lundgren et al. 2013).

Vendors reported a variety of symptoms as being the most prevalent - headache (43\%), followed by eye redness (40\%), joint pain $(39 \%)$, general weakness $(37 \%)$, backache (35\%), breathlessness (31\%), and eye watering (31\%). These health issues may be attributed to long working hours in the outdoor environment and consequent exposure to traffic emissions and road dust (Nomnual and Shendell 2017; Lawin et al. 2016; Amegah and Jaakola 2016; Xiang et al. 2014a). In a similar study, 55\% of roadside shopkeepers in Bhopal, Madhya Pradesh, in high traffic areas, complained of at least one respiratory symptom: bronchial asthma, chronic bronchitis, breathlessness, or cough (De et al. 2019). Furthermore, increasing levels of exposure to traffic-related air pollutants like VOCs, $\mathrm{NO}_{2}, \mathrm{CO}$, and $\mathrm{PM}_{2.5}$ increased the odds of the development of symptoms like eye irritation, phlegm, tightness in the chest, and other issues in the upper respiratory systems among street vendors (Kongtip et al. 2006). These circumstances indicate that personal protective equipment should be used by outdoor workers and that awareness is required to be created 
among them (Bajaj et al. 2017; Nomnual and Shendell 2017; Kongtip et al. 2006).

Among street sweepers, musculoskeletal problems, i.e., joint pain $(\sim 40 \%)$, backache $(38 \%)$, and shoulder pain $(36 \%)$, were the most prevalent. This outcome can be attributed to the fact that their jobs also involve physically strenuous work and ergonomic problems, rather than just exposure to air pollution or extreme weather conditions (Hanklang et al. 2014). Pintakham and Siriwong (2015) reported the prevalence of ergonomic problems among $89.3 \%$ of the street sweepers in Chiang Rai, Thailand. Other symptoms such as headache (38\%) and general weakness $(37 \%)$ were also common among them. Furthermore, the prevalence of respiratory problems such as breathlessness $(25 \%)$ and chronic cough $(24 \%)$ could be due to their exposure to dust particles and bioaerosols. For instance, in Nagpur, respiratory symptoms (15\%) were the highest among sweepers, followed by cardiovascular $(10 \%)$ and ophthalmic symptoms (9\%). Upper respiratory tract infection, chronic bronchitis, and asthma were more prevalent than in the control group because of occupational exposure to dust, as well as a smoking habit (Sabde and Zodpey 2008). El-Wahab et al. (2014) reported a higher prevalence of skin problems, respiratory disorders, pathogen infestations, and work-related injuries among municipality workers compared to control groups. Such health risks faced by these workers highlight the fact that such occupational exposure can be countered or reduced by the use of personal protective equipment like masks and goggles (Sabde and Zodpey 2008).

\section{Extreme weather events}

The results of the present study suggest that outdoor workers are at a greater risk of heat-related illnesses such as heat exhaustion, headache, nausea, cramps, and rashes. The critical reasons are the lack of facilities that can provide some respite from excess heat and shelters with ventilation (Schulte et al. 2016; Xiang et al. 2014a; Nag et al. 2013 Lundgren et al. 2012). Various other researchers have found similar impacts of extreme weather events on the health of outdoor workers. For instance, in North Korea, 62\% of cases of heat-related illnesses among outdoor workers occurred during heatwave events (Park et al. 2017). Similarly, heat stress due to hot ambient conditions is known to impact over 1 billion workers worldwide. One-third of these workers suffer negative health impacts, increased likelihood of mortality and morbidity, and adverse pregnancy outcomes. High heat stress can also affect mental health and impact physical working ability, productivity, and motorcognitive performance (Ebi et al. 2021).

Thus, occupational exposure to heat stress should be recognized as a public health concern. While certain organizations like the National Institute of Occupational Safety and Health (NIOSH A Reminder from NIOSH: Stay Safe When Working Outdoors in Hot Weather, 2018), Region of Peel Public Health have formulated some guidelines for outdoor workers working during extreme weather events in their respective regions, there is a need for strong and collaborative international efforts must be made to mitigate these health impacts, especially in view of the rapidly changing global climate and the anticipated rise in heat stress (Flouris et al. 2018; Hot Weather Guidelines Indoor and Outdoor Workers, Region of Peel Public Health). Along with international action, we suggest that the concerned local and regional authorities formulate similar preventive guidelines and sensitize outdoor workers about the impacts of extreme weather events and methods of prevention, while also facilitating protective measures as well as the development of shelters and cooling facilities for outdoor workers.

\section{Pulmonary function test}

More significant impairment of lung function among sweepers than among the other occupational groups can be attributed to the nature of their job, which involves routine exposure to dust and particulate matter. Jhoncy et al. (2014) reported reduced values of FVC and $\mathrm{FEV}_{1}$, suggesting that dust inhalation during sweeping caused acute lung function impairment among sweepers and increased the risk of the development of pulmonary disorders among them. The higher the duration of exposure, the greater was the risk. In a study on the brick kiln and pottery workers, Laohasiriwong et al. (2017) reported mild to severe restriction of airways among the workers, owing to their exposure to dust and $\mathrm{PM}_{10}$. The results also suggested an increased risk of lung function impairment due to habits such as smoking. Various studies have also reported a similar association between smoking and impaired lung function, as well as the occurrence of health impacts such as lung inflammation, asthma, lung cancer, and other pulmonary disorders (Wang et. al. 2018; Strzelak et al. 2018). Thus, workers also need to be made aware of the health impacts of such practices on their health.

\section{Use of PPE}

Similar to our observations, sweepers were dissatisfied with their uniforms. Sabde and Zodpe (2008) reported that in Nagpur, none of the subject sweepers used any protective equipment, and there is no motivation for its use. From Bangkok, it has been reported that the use of ill-fitting and inappropriate PPE by street vendors actually led to a higher prevalence of disease symptoms (Noomnual and Shendell 2017). Thus, to safeguard their health from occupational 
exposure, outdoor workers need to be sensitized about the use of proper PPE, as well as the importance of

- appropriate types of masks as per the extent of occupational exposure;

- adequately fitting masks, and also clear instructions about how to wear and clean them, and dispose of them;

- gloves, headgear, and boots, particularly for sweepers.

Such sensitization and capacity building are even more necessary in the current period when the world is battling the COVID-19 pandemic, and the healthcare burden has increased manifold. Groups that are already vulnerable to socio-economic and health issues must be adequately trained and motivated to bring about a behavioral change among them, which can help them minimize occupational health impacts.

\section{Conclusion}

This study presented various health issues faced by outdoor workers that are attributable to their occupational exposure to air pollution and extreme weather events. Considering the prevalence of various health symptoms among the study population and existing literature, occupational exposure to ambient air pollution and extreme weather events can be said to impact the health of outdoor workers. Furthermore, personal habits and influencing factors such as age, smoking, tobacco consumption, preexisting health issues, and lack of use of adequate safety measures can also increase the susceptibility of these workers to the various occupational health risks. Also, the lack of proper mitigation measures and policies, long working hours, and varying work locations aggravate their exposure to air pollution and extreme conditions. On the basis of the literature and our own field observations, we suggest that the concerned Government authorities and occupational welfare organizations should emphasize the following:

Promoting the use of safety measures such as proper protective equipment, including respiratory masks, goggles, and other protective clothing.

Creating awareness among outdoor workers about the various occupational risks and health impacts.

Providing adequate training and capacity building to the workers regarding the use of protective measures and following preventive guidelines, as well as monitoring whether these practices being followed by the workers.

Formulating local, national, and global mitigation policies and preventive guidelines.

Improvisation in the public health sector along with the development of adequate infrastructure for shelter during extreme weather events can also lead to the creation of healthy working conditions for outdoor workers (Working on a Warmer Planet, International Labor Organization, 2019).

Furthermore, similar studies can be conducted on other outdoor workers, as well as with larger sample size and longer time frame to gather greater insights into the occupational health scenario of the outdoor workers.

Supplementary Information The online version contains supplementary material available at https://doi.org/10.1007/s11356-022-18886-9.

Acknowledgements The authors would like to acknowledge the contribution of Manasvi Singha, Lady Irwin College, Delhi University, Mr. Shashank Pandey, and Ms. Tanya Sharma from TERI SAS for their help during data collection and compilation. We would like to thank Dr. Prateek Sharma, Dean, Academics, TERI School of Advanced Studies, for his constant support and guidance. We would also like to thank Mr. Ved Prakash Sharma, TERI, and Mr. Govind Marwari, Maulana Azad Medical College, for their technical assistance in spirometry.

Author contribution VB and AB conducted fieldwork, data analysis, and first draft; SJ worked on the research design, methodology, first draft, and project management; $\mathrm{CJ}$ on research design and manuscript review; AKS and AM on research design, data analysis, training for medical tests, and their analysis; all authors wrote parts of the script, read and approved the final version.

Data availability The data used in this manuscript is provided in the supplementary information. If further information is required, it will be provided on request.

\section{Declarations}

Ethics approval thical approval from any board was not required because we have not taken any biosamples of the respondents, information taken during the survey was completely voluntary and consent of the respondents was taken during this survey to use analyzed data in the research and publication without highlighting identity or personal information.

Consent for publication Not applicable.

Competing interests The authors declare no competing interests.

\section{References}

Abou-ElWafa HS, El-Bestar SF, El-Gilany AH, Awad El-Toraby EES (2014) Respiratory disorders among municipal solid waste collectors in Mansoura, Egypt: a comparative study. Arch Environ Occup Health 69:100-106

Aggarwal P, Jain S (2015) Impact of air pollutants from surface transport sources on human health: a modeling and epidemiological approach. Environ Int 83:146-157

Ahmedabad Municipal Corporation (2016) Heat Action Plan 2016: Guide to extreme heat planning in Ahmedabad, India.

AK Amegah G Dakuu P Mudu JJ Jaakkola 2021 Particulate matter pollution at traffic hotspots of Accra, Ghana: levels, exposure experiences of street traders, and associated respiratory and cardiovascular symptoms J Expo Sci Environ Epidemiolhttps://doi. org/10.1038/s41370-021-00357-X 
Amegah AK, Jaakkola JJ (2016) Street vending and waste picking in developing countries: a long-standing hazardous occupational activity of the urban poor. Int J Occup Environ Health 22:187-192

Apte JS, Kirphstetter WT, Reich HA, Deshpandey SJ, Kaushik G, Phel A et al (2011) Concentrations of fine, ultrafine and black carbon particle in auto-rickshaws in New Delhi. Atmos Environ 45:4470-4480

Babu VK, Damodar KS (2017) Effect of outdoor air pollution on pulmonary function of non-smoking auto-rickshaw drivers in Bangalore. Int J Clin Exp Physiol 4:30-33

Bajaj N, Sharma T, Suneja D, Jain S, Kumar P (2017) Determinants of respiratory and cardiovascular health effects in traffic policemen: a perception-based comparative analysis. J Transp Health 4:30-39

Barreiro TJ, Perillo I (2004) An approach to interpreting spirometry. Am Fam Physician 69:1107-1114

Biel R, Danieli C, Shekarrizfard M, Minet L, Abrahamowicz M et al (2020) Acute cardiovascular health effects in a panel study of personal exposure to traffic-related air pollutants and noise in Toronto, Canada. Sci Rep 10:1-12

Caronia RJ (2017) Restrictive lung disease. http://emedicine.medsc ape.com/article/301760-overview. Accessed on 11 October 2017

Carvalho RB, Carneiro MFH, Barbosa F, Batista BL, Simonetti J, Amantéa SL, Rhoden CR (2018) The impact of occupational exposure to traffic-related air pollution among professional motorcyclists from Porto Alegre, Brazil, and its association with genetic and oxidative damage. Environ Sci Pollut Res 25:1-12

Census of India (2011) http://www.censusindia.gov.in/2011census/ maps/atlas/07part1. Accessed on 08 September 2018

Chashchin VP, Siurin SA, Gudkov AB, Popova ON, Voronin A (2014) Influence of industrial pollution of ambient air on health of workers engaged into open air activities in cold conditions. Med $\mathrm{Tr}$ Prom Ekol 9:20-26

Cullinan P, Muñoz X, Suojalehto H, Agius R, Jindal S, Sigsgaard T, Blomberg A, Charpin D, Annesi-Maesano I, Gulati M, Kim Y (2017) Occupational lung diseases: from old and novel exposures to effective preventive strategies. Lancet Respir Med 5:445-455

De S, Kushwah GDS, Dharwey D, Shanmugasundaram D (2019) Respiratory morbidity of roadside shopkeepers exposed to trafficrelated air pollution in Bhopal, India. J Health Pollut 9(21).

Ebi KL, Capon A, Berry P et al (2021) Hot weather and heat extremes: health risks. The Lancet 398(10301):698-708

El-Wahab EWA, Eassa SM, Lotfi SE, El Masry SA, Shatat HZ, Kotkat AM (2014) Adverse health problems among municipality workers in Alexandria (Egypt). Int J Prev Med 5:545-556

Eneyew B, Sisay T, Gizeyatu A, Lingerew M, Keleb A, Malede, A, et. al. (2021) Prevalence and associated factors of acute respiratory infection among street sweepers and door-to-door waste collectors in Dessie City, Ethiopia: a comparative cross-sectional study. PloS One 16(5).

Flouris AD, Dinas PC, Ioannou LG, Nybo L, Havenith G, Kenny GP, Kjellstrom T (2018) Workers' health and productivity under occupational heat strain: a systematic review and meta-analysis. Lancet Planet Health 2(12): e521-e531

Frank E, Harrell Jr (2015) Regression modelling strategies - with applications to linear models, logistic and ordinal regression, and survival analysis. Springer Series in Statistics, Springer, Cham, pp 219-74.

Statistical Abstract of Delhi, 2016, GNCTD (2017) http://www.delhi. gov.in/wps/wcm/connect/f508bc8046667b0e9cf6bcf5a4ed47e7/ Stattistical+Abstract+of+Delhi+2014.pdf?MOD=AJPERES\& $1 \mathrm{mod}=66436406 \& \mathrm{CACHEID}=\mathrm{f} 508 \mathrm{bc} 8046667 \mathrm{~b} 0 \mathrm{e} 9 \mathrm{cf} 6 \mathrm{bcf5a}$ 4ed47e7 Accessed 27 September 2018.

Government of National Capital Territory of Delhi (GNCTD) (2012) delhi.gov.in/wps/wcm/connect/DOIT_DC_SOUTH/ dc\%28south $\% 29 /$ our+services/notification+for+formation+of+ 11+districts. Accessed 08 September 2018

Hajat S, Chalabi Z, Wilkinson P, Erens B, Jones L, Mays N (2016) Public health vulnerability to wintertime weather: time-series regression and episode analyses of national mortality and morbidity databases to inform the cold weather plan for England. Public Health 137:26-34

Hanklang S, Kaewboonchoo O, Silpasuwan P (2014) Musculoskeletal disorders among Thai women in construction-related work. Asia Pac J Public Health 26:196-202

Hot Weather Guidelines Indoor and Outdoor Workers, Region of Peel Public Health. Available at https://www.peelregion.ca/health/heat/ pdfs/hwg-workers.pdf. Accessed on November 17, 2021.

Jain S (2017) Exposure to in-vehicle respirable particulate matter in passenger vehicles under different ventilation conditions and seasons. Sustain Environ Res 27:87-94

Jain S, Aggarwal P, Sharma P, Kumar P (2016) Vehicular exhaust emissions under current and alternative future policy measures for megacity Delhi, India. J Transp Health 3:404-412

S Jain V Barthwal 2021 Health impact assessment of auto rickshaw and cab drivers due to exposure to vehicular pollution in Delhi: an integrated approach Environ SciPollut Reshttps://doi.org/10. 1007/s11356-021-16058-9

Johncy S, Dhanyakumar G, Vivian Samuel T, Ajay KT, Suresh YB (2013) Acute lung function response to dust in street sweepers. J Clin Diagn Res 7:2126-2129

Johnson JD, Theurer WM (2014) A stepwise approach to the interpretation of pulmonary function tests. Am Flam Physician 89: 359-66.

Kolluru SSR, Patra AK, Sahu SP (2018) A comparison of personal exposure to air pollutants in different travel modes on national highways in India. Sci Total Environ 619:155-164

Kongtip P, Thongsuk W, Yosook W, Chantanakul S (2006) Health effects of metropolitan traffic related air pollutants on street vendors. Atmos Environ 40:7138-7145

Kravchenko J, Abernethy PA, Fawzy M, Lyerly HK (2013) Minimisation of heatwave morbidity and mortality. Am J Prev Med 44:274-282

Kumar A, Mishra RK (2018) Human health risk assessment of major air pollutants at transport corridors of Delhi, India. J Transp Health 10:132-143

Kumar P, Jain S, Sharma P, Gujar BR, Khare M, Morawska L, Britter R (2013) New directions: can a "blue sky" return to Indian megacities? Atmos Environ 71:198-201

Landrigan PJ, Fuller R, Acosta NJR, Adeyi O, Arnold R, Basu NN et al (2017) The Lancet commission on pollution and health. The Lancet 391:1-51

Laohasiriwong W, Srathonghon W, Phajan T, Assana S, Intamat S (2017) Dust exposure and lung function of workers in the brick and clay pottery factories in the Northeast of Thailand. Int J Environ 74:1001-1012

Laumbach RJ, Kipen HM (2012) Respiratory health effects of air pollution: update on biomass smoke and traffic pollution. J Allergy Clin Immunol 129:3-11

Lawin H, Agodokpessi G, Ayelo P, Kagima J, Sonoukon R, Awopeju O (2016) A cross sectional with an improved methodology to assess occupational air pollution exposure and respiratory health in motorcycle taxi driving. Sci Total Environ 550:1-5

Levy, BS and Roelofs C (2019). Impacts of climate change on workers' health and safety. Oxford Research Encyclopedia of Global Public Health.

Li X, Chow KH, Zhu Y, Lin Y (2016) Evaluating the impacts of hightemperature outdoor working environments on construction labor productivity in China: a case study of rebar workers. Build Environ 95:42-52

Liu WT, Ma CM, Liu IJ, Han BC, Chuang HC, Chuang KJ (2015) Effects of commuting mode on air pollution exposure and 
cardiovascular health among young adults in Taipei. Taiwan Int $\mathbf{J}$ Hyg Environ Health 218:319-323

Liu T, Marlier ME, DeFries RS, Westervelt DM, Xia KR, Fiore AM, Mickley LJ, Milly CDH, G, (2018) Seasonal impact of regional outdoor biomass burning on air pollution in three Indian cities: Delhi, Bengaluru, and Pune. Atmos Environ 172:83-92

Loomis D, Grosse Y, Lauby-Secretan B, El Ghissassi F, Bouvard V, Benbrahim-Tallaa L, Guha N, Baan R, Mattock H, Straif K (2013) The carcinogenicity of outdoor air pollution. Lancet Oncol 14:1262-1263

Lundgren K, Kuklane K, Gao C, Holmer I (2013) Effects of heat stress on working populations when facing climate change. Ind Health $51: 3-15$

Miller MR, Hankinson JATS, Brusasco V, Burgos F, Casaburi R, Coates A, Crapo R, Enright PV, Van Der Grinten CPM, Gustafsson P, Jensen R (2005) Standardisation of spirometry. Eur Respir J 26:319-338

Moda HM, Alshahrani A (2018) Assessment of outdoor workers perception working in extreme hot climate. Handbook of Climate Change Communication. Springer, Cham, pp 183-195

Monrad M, Sajadieh A, Christensen JS, Ketzel M, Raaschou-Nielsen O, Tjønneland A, Overvad K, Loft S, Sørensen M (2017) Longterm exposure to traffic-related air pollution and risk of incident atrial fibrillation: a cohort study. Environ Health Perspect 125:422-427

National Institute of Environmental Health Sciences (NIEHS) (2015) a report assessing how climate change will impact worker health and how to prepare for these impacts. Electronic library of construction occupational safety and health. Available at: https:// www.niehs.nih.gov/news/events/pastmtg/hazmat/assets/2014/ wtp_2014_sam_assess_report_508.pdf. Accessed on 12 November 2020 .

Nag PK, Dutta P, Nag A, Kjellstrom T (2013) Extreme heat events: perceived thermal response of indoor and outdoor workers. Int $\mathrm{J}$ Cur Res Rev 5:65-78

Noomnual S, Shendell GD (2017) Young adult street vendors and their adverse respiratory outcomes in Bangkok, Thailand. Saf Health Work 8:407-409

Park J, Kim Y, Oh I (2017) Factors affecting heat-related diseases in outdoor workers exposed to extreme heat. Ann Occup Environ Med 29(1):1-6

Pintakham K, Siriwong W (2015) Prevalence rate and risk factors associated with health hazards to select the magnitude of health problems among street sweepers in Chiang Rai Province. Thailand. ISOR J Environ Sci Toxicol Food Technol 9:15-18

Pintakham K, Siriwong W (2016) Prevalence and risk factors associated with musculoskeletal discomfort among street sweepers in Chiang Rai province, Thailand. J Health Res 30:207-213

Puri P, Nandar S, Kathuria S, Ramesh V (2017) Effects of air pollution on the skin: a review. Indian J Dermatol Venereol Leprol 83(4):415-423

Rana R, Singhal R (2015) Chi-square test and its application in hypothesis testing. IJ Cardiol Sci 1(1):69-71

Raval A, Dutta P, Tiwari A, Ganguly PS, Sathish LM, Mavalankar D, Hess J (2018) Occupational heat exposure of traffic police workers in Ahmedabad. India Occup Environ Med 22(3):144-151
A Reminder from NIOSH: stay safe when working outdoors in hot weather (2018). Available at https://www.cdc.gov/niosh/updates/ upd-07-02-18.html. Accessed on November 17, 2021.

Sabde YD, Zodpey SP (2008) A study of morbidity pattern in street sweepers: a cross-sectional study. Indian J Community Med 33:224-228

Schikowski T, Hüls A (2020) Air pollution and skin aging. Curr Environ Health Rep 7(1):58-64

Schulte AP, Bhattacharyaa A, Butler RC, Chunc HK, Jacklitsch B, Jacobs T, Kieferb M, Lincoln J, Pendergrassa S, Shire J, Watson J, Wagnerg R (2016) Advancing the framework for considering the effects of climate change on worker safety and health. J Occup Environ Hyg 13:847-867

Sharma M, Nepalia R (2020) A cross sectional study of pulmonary function tests in street cleaners of Udaipur region. Indian Journal of Clinical Anatomy and Physiology 7:173-176

Shih JH, Fay MP (2017) Pearson's chi-square test and rank correlation inferences for clustered data. Biometrics 73(3):822-834

Sreejesh S, Mohapatra S, Anusree MR (2014) Binary logistic regression. Business Research Methods. Springer, Cham, pp 245-258

Strzelak A, Ratajczak A, Adamiec A, Feleszko W (2018) Tobacco smoke induces and alters immune responses in the lung triggering inflammation, allergy, asthma and other lung diseases: a mechanistic review. Int J Environ Res Public Health 15:5-1033

Tigala S, Sharma AR, Sachdeva K (2018) Health risk assessment due to biomass smoke exposure in Indian indoor environment: an empirical approach using lung deposition model. Sci Total Environ 640:935-942

Tiwari S, Thomas A, Rao P, Chate DM, Soni VK, Singh S, Ghude SD, Singh D, Hopke PK (2018) Pollution concentrations in Delhi India during winter 2015-16: a case study of an odd-even vehicle strategy. Atmos Pollut Res 9(6):1137-1145

Tonne C (2017) A call for epidemiology where the air pollution is. Lancet Planet Health 1:355-356

Wang C, Xu J, Yang L, Xu Y, Zhang X, Bai C, Kang J, Ran P, Shen H, Wen F, Huang K (2018) Prevalence and risk factors of chronic obstructive pulmonary disease in China (the China Pulmonary Health [CPH] study): a national cross-sectional study. The Lancet 391(10131):1706-1717

Working on a Warmer Planet, International Labour Organization 2019. Available at: https://www.ilo.org/wcmsp5/groups/public/---dgrep orts/---dcomm/---publ/documents/publication/wcms_711919.pdf, Accessed on 17 November 2021.

Xiang J, Bi P, Pisaniello D, Hansen A (2014a) Health impacts of workplace heat exposure: an epidemiological review. Ind Health 52:91-101

Xiang J, Bi P, Pisaniello D, Hansen A (2014b) The impact of heatwaves on workers' health and safety in Adelaide, South Australia. Environ Res 133:90-95

Publisher's note Springer Nature remains neutral with regard to jurisdictional claims in published maps and institutional affiliations. 